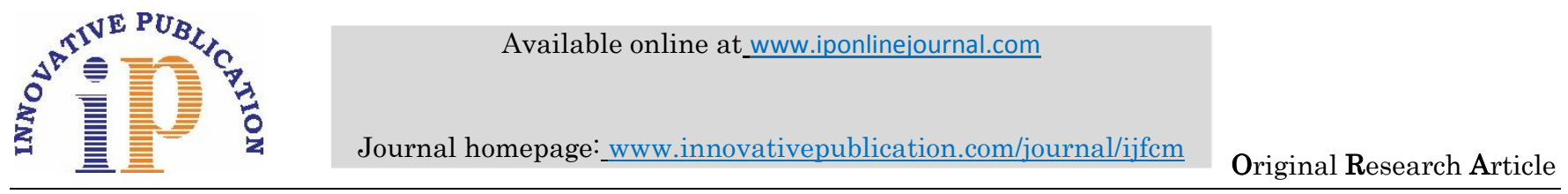

\title{
Prevalence and socioeconomic determinants of prehypertension and hypertension in Aligarh
}

\author{
Riyaz Ahamed Shaik ${ }^{1 *}$ Athar Ansari ${ }^{2}$, Usama B Ghaffar ${ }^{3}$ \\ ${ }^{1,3}$ Assistant Professor, ${ }^{2}$ Professor, ${ }^{1,2}$ Dept. of Community Medicine, ${ }^{3}$ Dept. of Pathology, ${ }^{\mathbf{1}}$ Koppal Institute of medical sciences Koppal, \\ Karnataka, ${ }^{2}$ Jawaharlal Nehru Medical College (JNMC), Aligarh Muslim University (AMU), Aligarh, Uttar Pradesh, India, ${ }^{3}$ Majmaah \\ University, Al Majmaah, Saudi Arabia
}

\begin{abstract}
Introduction: High blood pressure is the commonest risk factor for cardiovascular disease and is a major contributor to avoidable death and disease in India. The present study was carried out with an objective to study the prevalence of hypertension and prehypertension and sociodemographic correlates in rural and urban areas.

Materials and Methods: The present community based cross sectional study was conducted in the field practice areas of the Urban Health Training Centre (UHTC) and Rural Health Training Centre (RHTC), Department of Community Medicine, Jawaharlal Nehru Medical College, Aligarh Muslim University, Aligarh, Uttar Pradesh, India. Systemic random sampling to include subjects was used. Six hundred and forty subjects were chosen for the study. The study was carried out for one year. Data were analyzed with SPSS version 13.

Results: The overall prevalence of hypertension and prehypertension in our study was $19.7 \%$ and $53.7 \%$ respectively. The prevalence of high blood pressure showed a significantly increasing trend with increasing age in both males and females. Significant association of hypertension with sociodemographic variables such as occupation, income, locality and social class was noted.

Conclusion: High prevalence of prehypertension and hypertension calls for urgent preventive and treatment measures which are cost effective for early diagnosis and improve the availability of basic diagnostics at primary health care level.
\end{abstract}

Keywords: Hypertension, Pre-hypertension, Prevalence, Socio-demographic factors.

\section{Introduction}

Hypertension is a major risk factor for cardiovascular disease and is responsible for at least $45 \%$ of deaths due to heart disease and $51 \%$ of deaths due to stroke. ${ }^{1}$ According to World Health Organization, the worldwide burden of hypertension may be as much as 1 billion individuals and approximately 7.1 million deaths per year may be attributed to hypertension. In addition, suboptimal blood pressure (>115mm Hg of SBP) is number one attributable risk factor about $62 \%$ of cerebrovascular diseases and $49 \%$ of ischemic heart disease. ${ }^{2}$ The prevalence of hypertension in the last six decades has increased from $2 \%$ to $25 \%$ among urban residents and from $2 \%$ to $15 \%$ among the rural residents in India. According to Directorate General of Health Services, Ministry of Health and Family Welfare, Government of India, the overall prevalence of hypertension in India by 2020 will be $159.46 / 1000$ population. $^{3}$

Blood pressure (BP) is directly associated with risks of several types of cardiovascular disease, and the associations of BP with disease risk are continuous; indicating that large proportions of most populations have nonoptimal BP values. ${ }^{4}$ The seventh Report of the Joint National Committee on Prevention, Detection, Evaluation, and Treatment of High Blood Pressure (JNC7) defines hypertension as blood pressure $>140 / 90 \mathrm{mmHg}$. Persons with blood pressure above optimal levels, but not clinical hypertension (systolic blood pressure of 120-139 $\mathrm{mm} \mathrm{Hg}$ or diastolic blood pressure of $80-89 \mathrm{~mm} \mathrm{Hg}$ ), are defined as having "prehypertension". 5 Persons with prehypertension have a greater risk of developing hypertension than do those with lower blood pressure levels. ${ }^{6}$ Patients with Prehypertension (120-139/80-89 $\mathrm{mmHg}$ ) have an increased risk of cardiovascular morbidity and mortality compared with patients who have normal blood pressure. ${ }^{7,8}$ Recent epidemiological studies carried out using above criteria show increased prevalence of prehypertension and hypertension in both urban and rural areas of India. ${ }^{9-12}$ Hypertension is a controllable disease and a $2 \mathrm{mmHg}$ population-wide decrease in BP can prevent 151,000 stroke and 153,000 coronary heart disease deaths in India. ${ }^{13}$ In developing countries, preventability of prehypertension deteriorating into hypertension could have substantial positive impact on burden of cardiovascular diseases and socioeconomic domain of the country. Hence this study therefore attempts to study the prevalence of hypertension and prehypertension and its socoidemographic correlates in rural and urban areas of Aligarh.

\section{Materials and Methods}

The present community based study was conducted in the field practice area of the Urban Health Training Centre and Rural Health training Centre, Department of Community Medicine, Jawaharlal Nehru Medical College, Aligarh Muslim University, Aligarh, Uttar Pradesh. The urban health training center (U.H.T.C) has four registered periurban localities with 1670 households and a registered

*Corresponding Author: Riyaz Ahamed Shaik, Dept. of Forensic Medicine, Koppal Institute of medical sciences Koppal, Karnataka, India

Email: drriyazahamed@gmail.com

http://doi.org/10.18231/J.IJFCM.2019.035 
population of 10,250 . The rural health training center (R.H.T.C.) has seven registered villages having 2400 households with a registered population of 14,600 . Approval for study was passed from the institutional board of study meeting. The estimated sample size was calculated according to the formula: $\mathrm{N}=4 \mathrm{pq} / \mathrm{d}^{\wedge} 2$ where $\mathrm{p}$ is the prevalence of hypertension, $\mathrm{q}=1-\mathrm{p}$ and $\mathrm{d}$ is absolute error. Taking the prevalence of hypertension. ${ }^{12}$ as $32 \%$ and $15 \%$ nonresponsive rate, the sample size was approximated to 640. The sample included all individuals aged between 18 to 65 years .Systematic random sampling was done in the respective areas and sample was drawn from each area. We drew $60 \%$ and $40 \%$ of the sample size from the rural population and urban population respectively. Proportionate to population size we had a sample of 340 subjects from the RHTC and 256 subjects from the UHTC. A preformed proforma questionnaire was filled up by house to house visit till 640 subjects were enrolled in the study. Blood pressure (systolic and diastolic phase V of Korotkoff) was measured using a standard mercury sphygmomanometer in the right arm in a sitting posture, after at least $5 \mathrm{~min}$ of rest. It was repeated after $5 \mathrm{~min}$ and the second reading was used for analysis. Blood pressure variation was between 2-4 mm of $\mathrm{Hg}$. Hypertension was diagnosed according to JNC 7 criteria.[5] Normal blood pressure was defined as systolic blood pressure $<120 \mathrm{~mm} \quad \mathrm{Hg}$ and diastolic blood pressure $<80 \mathrm{~mm} \mathrm{Hg}$ and pre-hypertension as systolic blood pressure between 120 to $139 \mathrm{~mm} \mathrm{Hg}$ or diastolic blood pressure between 80 to $89 \mathrm{~mm} \mathrm{Hg}$. Hypertension was defined as systolic blood pressure $>140 \mathrm{~mm} \mathrm{Hg}$ or diastolic blood pressure $>90 \mathrm{~mm} \mathrm{Hg}$. All subjects currently on anti-hypertensive medications, or having written prescriptions of anti-hypertensive drugs, were classified as "hypertensive", irrespective of their current blood pressure reading. The social class of the subject was determined using the Modified Prasad Scale. Social classes I and II were categorized into upper class, class III as middle class and class IV and V of Modified Prasad's classification were categorized into lower class. ${ }^{14}$ Analysis was performed using SPSS version 13.0 (SPSS, Chicago, IL). Chi-square test was applied wherever applicable.

\section{Results}

The overall prevalence of hypertension and prehypertension in our study was $19.7 \%$ and $53.7 \%$ respectively. Prevalence of hypertension was higher in males $(22.0 \%)$ than females $(17.6 \%)$. About $53 \%$ of the subjects were of the both sexes were found to be in prehypertension category. Table 1 and Table 2 show the distribution of hypertension, mean SBP and mean DBP in different age groups in males and females respectively.

Table 1: Prevalence of hypertension among male subjects in different age groups

\begin{tabular}{|c|c|c|c|c|c|c|c|}
\hline \multirow[t]{2}{*}{ Criteria } & \multicolumn{7}{|c|}{ Age groups } \\
\hline & $\begin{array}{c}18-25 \\
(n=65)\end{array}$ & $\begin{array}{c}26-35 \\
(n=63)\end{array}$ & $\begin{array}{c}36-45 \\
(n=57)\end{array}$ & $\begin{array}{c}46-55 \\
(n=37)\end{array}$ & $\begin{array}{c}56-65 \\
(n=78)\end{array}$ & $\begin{array}{l}\text { Total } \\
(\mathbf{3 0 0})\end{array}$ & $\mathbf{P}$ \\
\hline Normal & $21(32.3)$ & $16(25.4)$ & $11(19.3)$ & $10(27.0)$ & $18(23.1)$ & $76(25.3)$ & $\chi^{2}-$ \\
\hline Prehypertension & $43(66.2)$ & $34(54.0)$ & $33(57.9)$ & 17(45.9) & $31(39.8)$ & $158(52.7)$ & 37.95 \\
\hline Stage 1 hypertension & $1(1.5)$ & $13(20.6)$ & $11(19.3)$ & $10(27.0)$ & $29(37.2)$ & $64(21.3)$ & $\mathrm{P}$ value \\
\hline Stage 2 hypertension & $0(0.0)$ & $0(0.0)$ & $2(3.5)$ & $0(0.0)$ & $0(0.0)$ & $2(0.7)$ & $<0.05$ \\
\hline Mean SBP \pm SD & $124.4 \pm 11.3$ & $126.2 \pm 11.7$ & $127.5 \pm 13.5$ & $133 \pm 16.5$ & $135 \pm 14.7$ & $129 \pm 13.8$ & 0.007 \\
\hline Mean DBP \pm SD & $81.2 \pm 9.3$ & $85.2 \pm 9.7$ & $86.0 \pm 11.1$ & $89.2 \pm 11.1$ & $90.2 \pm 9.5$ & $87.1 \pm 10.5$ & 0.001 \\
\hline
\end{tabular}

Table 2: Hypertension among female subjects in different age groups

\begin{tabular}{|c|c|c|c|c|c|c|c|}
\hline \multirow[b]{2}{*}{ Criteria } & \multicolumn{7}{|c|}{ Age groups } \\
\hline & $\begin{array}{c}18-25 \\
(n=73)\end{array}$ & $\begin{array}{c}26-35 \\
(n=75)\end{array}$ & $\begin{array}{c}36-45 \\
(n=69)\end{array}$ & $\begin{array}{c}46-55 \\
(n=73)\end{array}$ & $\begin{array}{c}56-65 \\
(n=50)\end{array}$ & $\begin{array}{c}\text { Total } \\
(\mathbf{N}=\mathbf{3 4 0})\end{array}$ & $\mathbf{P}$ \\
\hline Normal & $30(41.1)$ & $18(24.0)$ & $22(31.9)$ & $19(26.0)$ & $6(12.0)$ & $95(27.9)$ & $\chi^{2}-$ \\
\hline Prehypertension & $39(53.4)$ & $48(64.0)$ & $39(56.5)$ & $32(43.8)$ & $27(54.0)$ & $185(54.4)$ & 43.91 \\
\hline Stage 1 hypertension & $1(1.4)$ & $9(12.0)$ & $8(11.6)$ & $16(21.9)$ & $15(30.0)$ & $49(14.4)$ & $P$ value \\
\hline Stage 2 hypertension & $3(4.10)$ & $0(0.0)$ & $0(0.0)$ & $6(8.2)$ & $2(4.0)$ & $11(3.2)$ & $<0.05$ \\
\hline Mean SBP \pm SD & $119.5 \pm 123$ & $121.2 \pm 14.2$ & $125.3 \pm 14.5$ & $134.3 \pm 16.5$ & $140.1 \pm 14.7$ & $124.2 \pm 11.2$ & 0.001 \\
\hline Mean DBP \pm SD & $81.2 \pm 9.3$ & $85.2 \pm 9.7$ & $86.0 \pm 11.1$ & $89.2 \pm 11.1$ & $90.2 \pm 9.5$ & $84.1 \pm 10.4$ & 0.001 \\
\hline
\end{tabular}

In the current study, the prevalence of hypertension increased significantly from age group 18-25 to 56-65yr. The Mean SBP and DBP reported in males was $129 \pm 13.8$ and $87.1 \pm 10.5$ respectively, and in females it was $124.2 \pm 11.2$ and $84.1 \pm 10.4$ respectively. Mean SBP and Mean DBP showed a predominant rising trend with increasing trend with age which was found to be highly significant. However, the mean SBP and DBP were lowest in the age group 18-25 years and increased with age. 


\section{Blood pressure and sociodemographic factors}

Based on blood pressure, subjects were dichotomized as hypertensives (BP $\geq 140 / 90 \mathrm{~mm} \mathrm{Hg}$ ) and nonhypertensives $(<140 / 90$ $\mathrm{mm} \mathrm{Hg}$ ) and studied with respect to different socio-demographic factors. The prevalence of hypertension was significantly associated with sociodemographic variables as shown in Table 3. The prevalence was more in male subjects who were semiprofessionals or professionals (55.5\%) and who had better qualification $(51.7 \%)$, whereas in case of females, it was more in unemployed $(52.4 \%)$ mostly elderly followed by unskilled laborers $(41.7 \%)$. Regarding the type of family there was no significant statistical association with raised blood pressure. Prevalence of high blood pressure is directly related to socioeconomic status. It was $53.6 \%$ in males belonging to upper SES compared to $18.4 \%$ in lower SES males. It follows the similar trends in females also.

Table 3: Hypertension by socio-demographic factors

\begin{tabular}{|c|c|c|c|c|}
\hline \multirow{2}{*}{ Criteria } & \multicolumn{2}{|c|}{ Males } & \multicolumn{2}{|c|}{ Females } \\
\hline & $\mathbf{n}$ & $(\%)$ & $\mathbf{n}$ & $(\%)$ \\
\hline \multicolumn{5}{|c|}{ Occupation } \\
\hline Unemployed & 40 & $7(17.5)$ & 21 & $11(52.4)$ \\
\hline Unskilled & 109 & $15(13.8)$ & 12 & $5(41.7)$ \\
\hline Semiskilled/Skilled & 46 & $1(2.2)$ & 2 & $0(0.0)$ \\
\hline Clerical & 69 & $23(33.3)$ & - & - \\
\hline Semiprofessional/Professional & 36 & $20(55.5)$ & 20 & $2(10.0)$ \\
\hline Housewife & - & - & 285 & $42(14.7)$ \\
\hline \multicolumn{5}{|c|}{$\chi^{2}=79.58, p$-value- $<0.05$} \\
\hline \multicolumn{5}{|c|}{ Education } \\
\hline No formal education & 79 & $7(8.9)$ & 173 & $26(15.0)$ \\
\hline Primary/Middle & 45 & $9(20.0)$ & 37 & $15(40.5)$ \\
\hline High / Intermediate & 118 & $20(16.9)$ & 86 & 12(13.9) \\
\hline Graduate/Above graduate & 58 & $30(51.7)$ & 44 & $7(15.9)$ \\
\hline \multicolumn{5}{|c|}{$\chi^{2}=82.70, p$-value $-<0.05$} \\
\hline \multicolumn{5}{|c|}{ Religion } \\
\hline Hindu & 128 & $31(24.2)$ & 112 & $24(21.4)$ \\
\hline Muslim & 170 & $35(20.6)$ & 226 & $36(15.9)$ \\
\hline Christian & 2 & $0(0.0)$ & 2 & $0(0.0)$ \\
\hline \multirow{2}{*}{\multicolumn{5}{|c|}{$\frac{\chi^{2}=13.58, p-\text { value }-<0.05 \quad \chi^{2}}{\text { Family type }}$}} \\
\hline & & ype & & \\
\hline Nuclear & 109 & $24(22.0)$ & 143 & $27(18.9)$ \\
\hline Joint & 191 & $42(22.0)$ & 197 & $33(16.8)$ \\
\hline \multicolumn{5}{|c|}{$\chi^{2}=3.82, p$-value $-<0.05$} \\
\hline \multicolumn{5}{|c|}{ Social class } \\
\hline Upper & 28 & $15(53.6)$ & 50 & $11(22.0)$ \\
\hline Middle & 39 & $8(20.5)$ & 59 & $11(18.6)$ \\
\hline Lower & 233 & $43(18.4)$ & 231 & $38(16.4)$ \\
\hline
\end{tabular}

\section{Discussion}

The results of present study reveal high prevalence of hypertension and its significant association with sociodemographic correlates and are corroborated by other studies. ${ }^{15-17}$ In Indians, studies conducted among urban population of Jaipur, hypertension was reported as $31 \%$ (men $30 \%$; women $34 \%$ ) and $36.9 \%$ (men $36.4 \%$; women $37.5 \%){ }^{16-17}$ The prevalence reported by our study was low compared to above studies, as these studies were carried out only in urban areas. It is noted the prevalence in men was higher than in women as reported by studies conduct6ed elsewhere. ${ }^{18-20}$

JNC 7 has created a new designation of prehypertension to identify those individuals in whom early intervention by applying healthy lifestyles could reduce BP, decrease rate of progression of BP of hypertensive levels with age, or prevent hypertension entirely. Our study revealed high prevalence of pre-hypertension $(53.7 \%)$. This was similar to that reported by other studies conducted in industrialized economies as well as from India. ${ }^{12,21,23}$ Even in the rural population in Assam, 54\% subjects had pre-hypertension and one-third had hypertension. ${ }^{23}$

On statistical analysis hypertension was found to show a positive association with education and income in the respondents, in both males and females, in our study (Table $3)$. This finding is opposite to the findings of researchers in developed countries. For example, a study in Chicago, observed trends in different age groups and reported an inverse relation between hypertension and education in a sample of 27,000 respondents aged 25-64 years. The above 
study also mentioned various other studies conducted in US which report similar findings. ${ }^{24}$

In India, a study on coronary risk factors with respect to social classes. Has found high prevalence of coronary risk factors (obesity, sedentary lifestyle and hypertension) exists in high social classes (people with better income, occupation and education. ${ }^{18}$ Lower risk in high social classes in developed countries appears to be because of better health education and increased spare time physical activity. In developing countries however, the situation is reverse because people in lower social classes are too poor to buy foods with high fat content, therefore eat less expensive foods like fruits and vegetables. Also they usually have physically demanding occupations, low serum cholesterol and other factors which may be protective.

\section{Conclusion}

Hypertension and prehypertension has emerged as a fairly important risk factor for target organ damage, and cardiovascular-related morbidity and mortality. In our study large numbers of young adults are in the prehypertension group and therefore are potential candidates for becoming hypertensive with advancing age. Despite advances in the prevention, detection, and treatment of prehypertension and hypertension, it remains an important public health challenge that adopts appropriate treatments in different degrees effectively. Integrated programmes must be established at the primary care level for management of these patients. Operational research is need of the hour to identify the gaps in implementing cost effective interventions available for addressing prehypertension and hypertension even in low resource settings at primary care level.

\section{Acknowledgment}

I would like to express my profound gratitude to all the participants.

\section{Conflict of Interest}

None.

\section{Source of Funding}

None.

\section{Ethical Approval}

Permission for the study was obtained from the College authorities prior to commencement

\section{References}

1. Causes of Death 2008. Geneva, World Health Organization (http:

//www.who.int/healthinfo/global_burden_disease/cod_2008.)

2. World Health Organization. The World Health Report 2002: Risks to Health 2002. Geneva: World Health Organization.

3. National Programme for Prevention and Control of Cancer, Diabetes, Cardiovascular diseases and Stroke (NPCDCS) Operational Guidelines. Directorate General of Health Services, Ministry of Health and Family Welfare, Government of India.
4. Deedwania P, Gupta R. Hypertension in South Asians. In: Izzo, Black (eds). Primer on Hypertension. American Heart Association, Dallas, USA, 2002.

5. Chobanian AV, Bakris GL, Black HR, Cushman WC, GreenLA, Izzo JL Jr, et al. The Seventh Report of the Joint National Committee on Prevention, Detection, Evaluation, and Treatment of High Blood Pressure: the JNC 7 Report. JAMA 2003; $289: 2560-72$.

6. Greenlund KJ, Croft JB, Mensah GA. Prevalence of heart disease and stroke risk factors in persons with prehypertension in the United States, 1999-2000. Arch Intern Med 2004; 164 : 2113-8.

7. H. A. Liszka, A. G. Mainous, D. E. King, C. J. Everett, and B. M. Egan, "Prehypertension and cardiovascular morbidity," Annals of Family Medicine, 3(4) : 294-99.

8. K.C.Ferdinand and R. S. Pacini, "New evidence confirms risks associated with prehypertension and benefits of therapeutic lifestyle changes in management," J Cardiometabolic Syndr 2007;2(4):302-4.

9. Gupta R, Guptha S, Gupta VP, Prakash H. Prevalence and determinants of hypertension in the urban population of Jaipur in Western India. J Hypertens 1995;13:1193-1200.

10. Gupta PC, Gupta R. Hypertension prevalence and blood pressure trends among 99,589 subjects in Mumbai, India. Abstract. Indian Heart J 1999;51:691.

11. Joseph A, Kutty VR, Soman CR. High risk for coronary heart disease in Thiruvananthapuram City: a study of serum lipids and other risk factors. Indian Heart $J$ 2000;52:29-35

12. Anand MP. Prevalence of hypertension amongst Mumbai executives. J Assoc Physicians India 2000;48 1200-1.

13. Yadav S, Boddula R, Genitta G, Bhatia V, Bansal B, Kongara $\mathrm{S}$ et al. Prevalence \& risk factors of pre-hypertension \& hypertension in anaffluent north Indian population. Indian $J$ Med Res 2008;128:712-20.

14. Rodgers A, Lawes C, MacMahon S. Reducing the globalburden of blood pressure related cardiovascular disease. J Hypertens 2000;18(1):S3-S6.

15. Kumar P. Social classification-need for constant updating. Ind J Comm Med 1993;8:59-61.

16. Clara C, Magnolia C, Krishna Raju P et al. Cardiovascular disease and risk factors among 345 adults in rural IndiaAndhra Pradesh Rural Health Initiative 2006;116:180-5.

17. Gupta R, Gupta VP, Sarna M. Prevalence of coronary heart disease and coronary risk factors in an urban Indian population: Jaipur Heart Watch 2. Indian Heart J 1995;46:5966.

18. Gupta R, Prakash H, Gupta VP et al. Prevalence and determinants of coronary heart disease in a rural population of India. J Clin Epidemiol 1997;50:203-9.

19. Singh RB, Beegom R, Mehta AS et al. Coronary risk factors and undernutrition, a double burden of diseases, in women during transition, in five Indian cities. Int J Cardiol 1999;69:139-47.

20. Beegom R, Singh RB. Association of higher saturated fat intake with higher risk of hypertension in an urban population of Trivandrum in South India. Int J Cardiol 1997;58:63-70.

21. Reddy SS, Prabhu GR. Prevalence and risk factors of hypertension in adults in an urban slum, Tirupathi, A.P. Indian J Comm Med 2005;30:84-6

22. Kearney PM, Whelton M, Reynolds K, Muntner P, Whelton $\mathrm{PK}, \mathrm{He} \mathrm{J}$ et al. Global burden of hypertension: analysis of worldwide data. Lancet 2005;365:217-23.

23. Wang Y, Wang QJ. The prevalence of pre-hypertension and hypertension among US adults according to the new joint national committee guidelines: New challenges of the old problem. Arch Intern Med 2004;164:2126-34. 
24. Hazarika NC, Narain K, Biswas D, Kalita HC, Mahanta J. Hypertension in the native rural population of Assam. Natl Med J India 2004;17:300-4.

25. Dyer AR, Stamler J, Shekelle RB. The relationship of education to blood pressure: Findings in 40,000 employed Chicagonians. Circ 1976;54:987-92.

How to cite this article: Shaik RA, Ansari A, Ghaffar UB. Prevalence and socioeconomic determinants of prehypertension and hypertension in Aligarh. Indian $J$ Forensic Community Med 2019;6(3):154-8. 